\title{
Long non-coding RNA IncC11 orf54-1 modulates neuroinflammatory responses by activating NF-KB signaling during meningitic Escherichia coli infection
}

\author{
Bojie Xu ${ }^{1,2}$, Ruicheng Yang ${ }^{1,2}$, Bo Yang ${ }^{1,2}$, Liang $\mathrm{Li}^{1,2}$, Jiaqi Chen ${ }^{1,2}$, Jiyang $\mathrm{Fu}^{1,2}$, Xinyi Qu ${ }^{1,2}$, Dong Huo ${ }^{1,2}$, \\ Chen Tan ${ }^{1,2,3,4}$, Huanchun Chen ${ }^{1,2,3,4}$, Zhong Peng ${ }^{1,2}$ and Xiangru Wang ${ }^{1,2,3,4^{*}}$ (i)
}

\begin{abstract}
Escherichia coli is the most common gram-negative pathogenic bacterium causing meningitis. It penetrates the blood-brain barrier (BBB) and activates nuclear factor kappa B (NF-kB) signaling, which are vital events leading to the development of meningitis. Long non-coding RNAs (IncRNAs) have been implicated in regulating neuroinflammatory signaling, and our previous study showed that E. coli can induce differential expression of IncRNAs, including IncC11 orf54-1, in human brain microvascular endothelial cells (hBMECs). The hBMECs constitute the structural and functional basis for the BBB, however, it is unclear whether IncRNAs are involved in the regulation of inflammatory responses of hBMECs during meningitic E. coli infection. In this study, we characterized an abundantly expressed IncRNA, IncC11 orf54-1, which was degraded by translocated coilin to produce mgU2-19 and mgU2-30 in hBMECs during E. coli infection. Functionally, IncC11 orf54-1-originated non-coding RNA mgU2-30 interacted with interleukin-1 receptor-associated kinase 1 (IRAK1) to induce its oligomerization and autophosphorylation, thus promoting the activation of NF-kB signaling and facilitating the production of pro-inflammatory cytokines. In summary, our study uncovers the involvement of IncC11 orf54-1 in IRAK1-NF-KB signaling, and it functions as a positive regulator of inflammatory responses in meningitic E. coli-induced neuroinflammation, which may be a valuable therapeutic and diagnostic target for bacterial meningitis.
\end{abstract}

Keywords: LncC11 orf54-1, Neuroinflammation, Brain microvascular endothelial cells, NF-kB signaling, Meningitic Escherichia coli, Blood-brain barrier

\section{Introduction}

Bacterial meningitis is an important life-threatening infection of the central nervous system (CNS), with high morbidity and mortality worldwide. Escherichia coli is the most common causative gram-negative pathogenic bacterium [1]. E. coli causes CNS dysfunction by

*Correspondence: wangxr228@mail.hzau.edu.cn

${ }^{1}$ State Key Laboratory of Agricultural Microbiology, College of Veterinary Medicine, Huazhong Agricultural University, Wuhan, Hubei, China

Full list of author information is available at the end of the article penetrating the blood-brain barrier (BBB), inducing local inflammation, increasing BBB permeability, and allowing leukocytes to migrate across the $\operatorname{BBB}[2,3]$. Brain microvascular endothelial cells (BMECs) constitute the structural and functional basis for the BBB $[1,4]$; their invasion by $E$. coli and the activation of inflammatory responses are vital steps in meningitis pathogenesis $[5,6]$. Activation of nuclear factor kappa B (NF- $\mathrm{KB}$ ) signaling, the master regulator of inflammatory responses [7], is a hallmark feature of bacterial meningitis [8]. Although accumulating evidence indicates the involvement of original author(s) and the source, provide a link to the Creative Commons licence, and indicate if changes were made. The images or other third party material in this article are included in the article's Creative Commons licence, unless indicated otherwise in a credit line to the material. If material is not included in the article's Creative Commons licence and your intended use is not permitted by statutory regulation or exceeds the permitted use, you will need to obtain permission directly from the copyright holder. To view a copy of this licence, visit http://creativecommons.org/licenses/by/4.0/. The Creative Commons Public Domain Dedication waiver (http://creativeco mmons.org/publicdomain/zero/1.0/) applies to the data made available in this article, unless otherwise stated in a credit line to the data. 
NF- $\mathrm{KB}$ signaling in modulating meningitic $E$. coliinduced CNS inflammation $[9,10]$, our current knowledge on the underlying regulatory mechanisms is limited.

LncRNAs are a novel class of transcripts that are longer than 200 nucleotides, with no or limited protein-coding potential [11]. They regulate diverse biological processes, such as imprinting control, cell differentiation, development, and tumor metastasis via interactions with DNA, RNA, or proteins [12-14]. In the field of immunology, increasing evidences have indicated that lncRNAs have crucial functions in regulating immune responses, including inflammation [15], which involve various inflammation-associated signaling pathways, such as the NF- $\mathrm{KB}$ pathway and the mitogen-activated protein kinase (MAPK) pathway [16, 17]. LncRNAs can work in different ways; however, the most studied mechanism is the functioning of IncRNAs as competitive endogenous RNAs to competitively sponge microRNA, thus inhibiting the degradation of mRNA [18]. For example, lncRNA H19 can sponge microRNA let-7a to regulate interleukin-6 (IL-6) expression and increase vascular inflammation [19]. Nevertheless, the regulatory mechanisms of more lncRNAs in meningitic E. coli-induced inflammatory responses remain to be systematically and comprehensively elucidated.

In the current study, we characterized an abundantly expressed lncRNA, lncC11orf54-1, in E. coli-challenged human BMECs (hBMECs). Meningitic infection in hBMECs by $E$. coli can dramatically degrade lncC11orf54-1 and produce non-coding RNA mgU2-19 and mgU2-30, which positively regulate $E$. coli-triggered pro-inflammatory cytokines production through IL-1 receptor-associated kinase 1 (IRAK1) autophosphorylation-mediated activation of the NF- $\mathrm{KB}$ signaling pathway. Thus, lncC11orf54-1 is an important inflammatory regulator of the NF-kB pathway during meningitic E. coli infection and may be an important therapeutic and diagnostic target in bacterial meningitis.

\section{Results}

\section{LncC11 orf54-1 displayed differential expression during meningitic $E$. coli infection}

To identify the lncRNAs involved in the inflammatory response induced by meningitic $E$. coli, we performed RNA-seq analysis in hBMECs challenged with or without E. coli PCN033 [20]. Reanalysis data showed that 280 known lncRNAs exhibited significant differences in hBMECs in response to meningitic E. coli infection $(\mathrm{p}<0.05)$. Among these lncRNAs, $54.7 \%$ were mapped to intergenic regions, followed by antisense regions (27.6\%), intronic regions (11.1\%), sense overlapping regions (4.2\%), and bidirectional regions (2.4\%) (Fig. 1a). The differentially expressed lncRNAs were subsequently filtered according to their transcript abundance. We identified 20 lncRNAs (Fig. 1b) with this method, among which lncC11orf54-1 was abundantly expressed in hBMECs. LncC11orf54-1 is a 353-nt lncRNA, and tissue distribution analysis in humans revealed that lncC11orf54-1 was abundantly expressed in the brain and adrenal gland (Fig. 1c). Three tools, including the coding potential capacitator $(\mathrm{CPC})$, coding potential, assessment tool (CPAT), ORF length, and GC content (LGC), were subsequently used to predict the protein-coding potential of lncC11 orf54-1. The prediction results supported the idea that lncC11orf54-1 has no protein-coding potential, similar to the potential coding analyses of the known lncRNAs MALAT1 and NEAT1, but opposite that of the typical protein-coding mRNAs such as TLR4, STAT1, and RelA (Fig. 1d). Together, these data show that lncC11orf54-1 is a brain-abundant lncRNA that is differentially expressed in hBMECs in response to meningitic $E$. coli infection.

\section{E. coli infection facilitated the degradation of IncC11 orf54-1}

The response of lncC11orf54-1 to E. coli infection was confirmed by qPCR, and the results showed that lncC11orf54-1 expression was significantly decreased in this process (Fig. 2a). LncC11orf54-1, an intronic lncRNA, is located on chromosome 11 of the human genome. It contains two smaller fragments, known as mgU2-19 and mgU2-30 (Fig. 2b). Determining the subcellular localization of a lncRNA can provide insights into its potential mechanism of action. The subcellular localization of lncC11orf54-1 in hBMECs was determined using nucleocytoplasmic separation and FISH assays. As shown in Fig. 2c, lncC11orf54-1 was primarily located in the cytoplasm. The nucleocytoplasmic separation assay showed that lncC11 orf54-1 could be detected in both nuclear and cytoplasmic compartments, but was highly enriched in the cytoplasm, similar to $18 \mathrm{~S}$ rRNA (Fig. 2d). As shown in Fig. 2a, when challenged with E. coli, the expression of lncC11orf54-1 was decreased in hBMECs, while that of mgU2-19 and mgU2-30 was not. To better assess the processed fragments generated on infection of hBMECs with $E$. coli, processing assays were run on formaldehyde agarose gels and Northern blotting. As shown in Fig. 2e, lncC11orf54-1 in hBMECs could be degraded by E. coli infection in a time-dependent manner; the expression of full-length lncC11orf54-1 was significantly decreased, while that of the processed mgU2-30 was increased. Taken together, these findings suggest that lncC11 orf54-1 is a cytoplasm-located lncRNA in hBMECs and is significantly degraded in response to meningitic E. coli infection. 


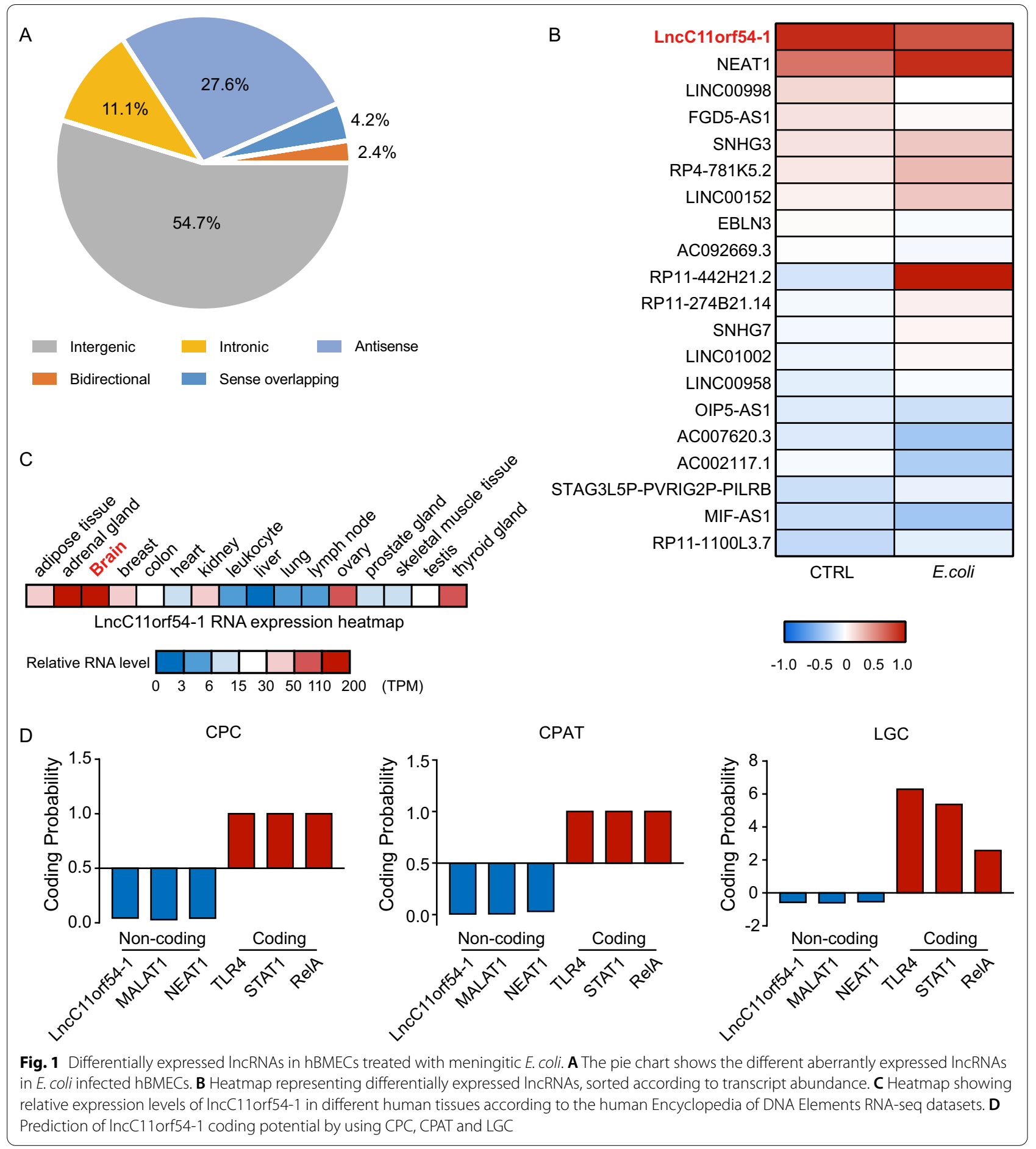

\section{E. coli infection led to the translocation of coilin to the cytoplasm}

Coilin is an RNase generally located in the nucleus, and RNAs like lncC11orf54-1 with GU-rich motif can be the target for coilin processing [21, 22]. Next, an immunofluorescence assay was performed to determine the mechanism underlying the involvement of coilin in the degradation of lncC11 orf54-1 in E. coli-infected hBMECs. We observed coilin translocation from the nucleus to the cytoplasm upon meningitic E. coli infection (Fig. 3a). The nuclear-to-cytoplasmic translocation of coilin was further determined by nucleocytoplasmic separation, 


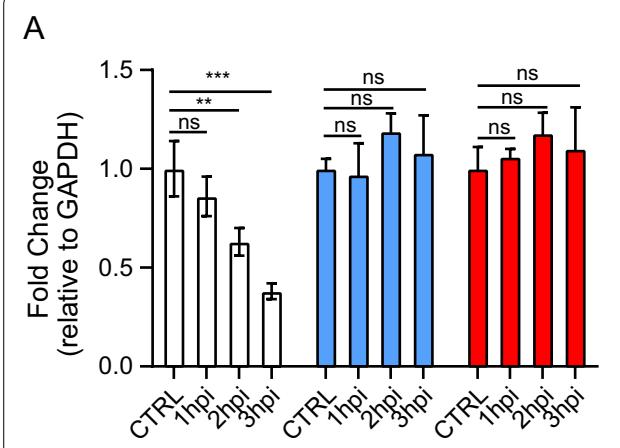

LncC11orf54-1 $\square$ mgU2-19
B

intronic IncRNA, ENSG00000254911.2

hg19 chr11 93454600..93455100+ [len 0.5kb ]

LncC11orf54-1 ENSG00000254911.2

GENCODEv19

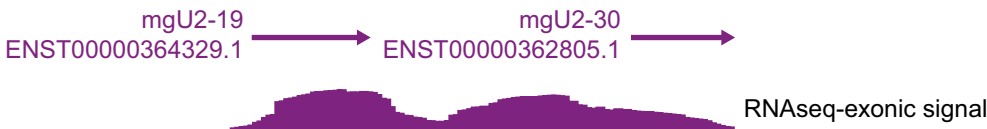
$\mathrm{mgU} 2-30$

C

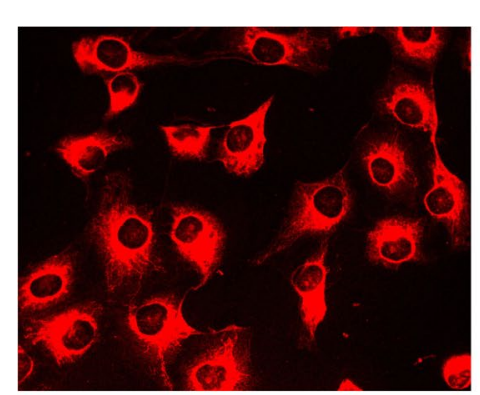

D

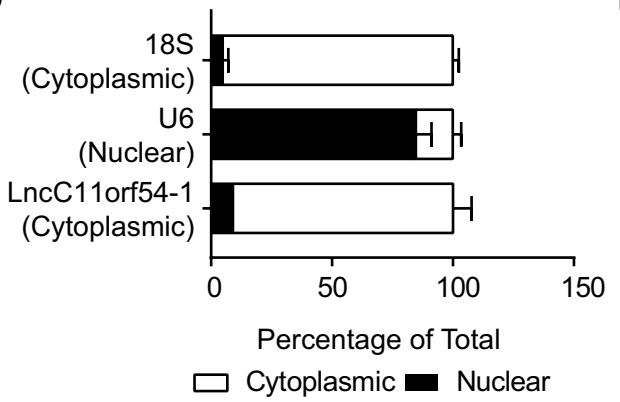

DAPI

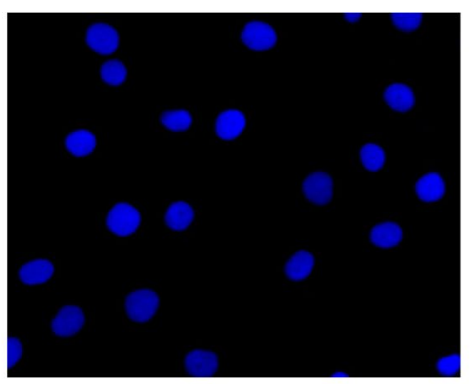

E

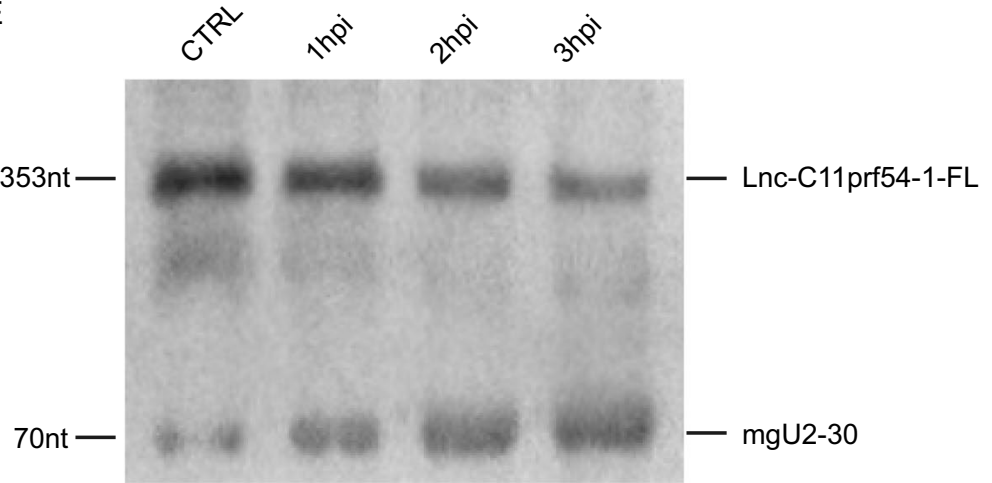

Fig. 2 LncC11 orf54-1 is downregulated in hBMECs with meningitic E. coli infection. A Expression of IncC11 orf54-1, mgU2-19, and mgU2-30 in hBMECs infected with E. coli for $0 \mathrm{~h}$ (control, lane 1), $1 \mathrm{~h}$ (lane 2), $2 \mathrm{~h}$ (lane 3) or $3 \mathrm{~h}$ (lane 4) using qPCR analysis. GAPDH was used as the internal reference for the qPCR. Data are presented as mean \pm SD from three independent experiments. ${ }^{* *} p<0.01$, and ${ }^{* * *} p<0.001$ by student's $t$-test. B Visualization of IncC11 orf54-1 in the ZENBU browser, showing exonic expression signaling in several different visualizations. C Subcellular localization of IncC1 1 orf54-1 (red) in hBMECs by FISH assay. 4',6-diamidino-2-phenylindole (DAPI) staining is shown in blue. Scale bars, $20 \mu \mathrm{m}$. D Nuclear/cytoplasmic localization analyses of IncC11 orf54-1 in hBMECs by qPCR. The $18 \mathrm{~S}$ and U6 distribution were selected as the cytoplasmic and nuclear control, respectively. E Expression of IncC11 orf54-1 and mgU2-30 in hBMECs infected with E. coli for $0 \mathrm{~h}$ (control, lane 1), $1 \mathrm{~h}$ (lane 2), $2 \mathrm{~h}$ (lane 3) or $3 \mathrm{~h}$ (lane 4) using Northern blotting

(See figure on next page.)

Fig. 3 Meningitic E. coli infection induces the translocation of coilin. A hBMECs were infected with or without meningitic E. coli, and the translocation of coilin (red) was detected by fluorescence microscopy. DAPI staining was shown in blue. Scale bars, $50 \mu \mathrm{m}$. B Nuclear-to-cytoplasmic redistribution analyses of coilin in E. coli-stimulated hBMECs. Western blotting analyses of coilin were performed on whole cell lysate, nuclear, and cytoplasmic fractions. GAPDH was used as the loading control for whole-cell lysate and cytoplasmic fractions, whereas for the nucleus fraction, lamin B was used as the loading control. C RNA FISH analyses and immunofluorescent analyses determining the co-localization of IncC11 orf54-1 (red) and coilin (green) in hBMECs with or without E. coli challenge. DAPI staining was shown in blue. Scale bars, $50 \mu \mathrm{m}$ 


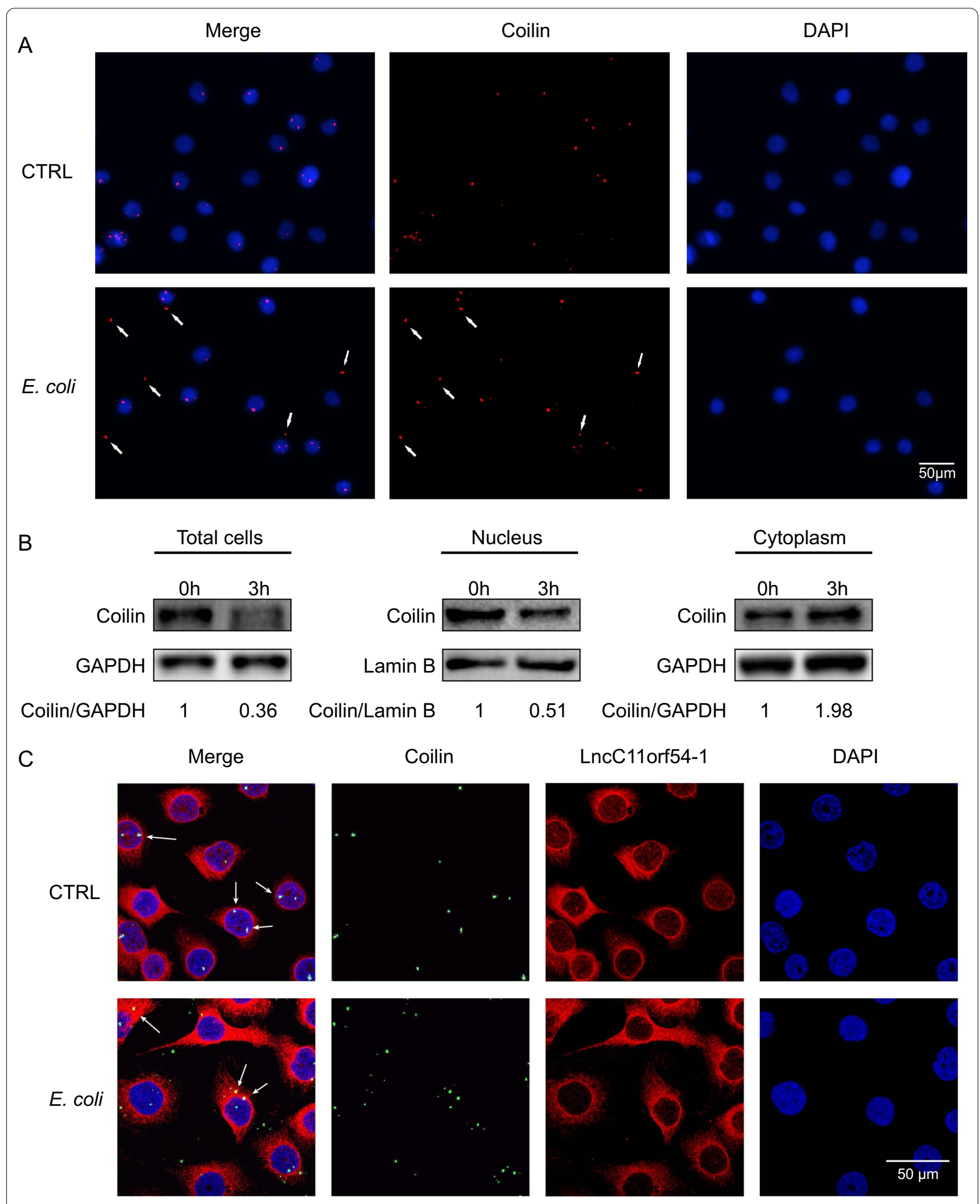

Fig. 3 (See legend on previous page.) 
followed by Western blotting. We measured the expression of coilin in the nucleus, cytoplasm, and total cells, and the results indicated that E. coli-treated hBMECs showed a prominent increase in the levels of cytoplasmic coilin, while levels of total coilin and nuclear coilin were decreased compared with control cells (Fig. 3b), suggesting that $E$. coli induced the transfer of coilin from the nucleus to the cytoplasm or even to the extracellular space. Moreover, RNA FISH and immunofluorescence assay also showed that the translocated coilin colocalized with lncC11orf54-1 in the cytoplasm (Fig. 3c). Thus, these results show that $E$. coli infection promotes the translocation of coilin to the cytoplasm and helps the processing of lncC11orf54-1 in hBMECs.

\section{The processed product mgU2-30 regulated the activation of NF-KB pathway}

To define the functional role of lncC11orf54-1 in meningitic $E$. coli-induced inflammatory responses in hBMECs, lncC11orf54-1 was overexpressed or knocked out in hBMECs. In E. coli-challenged hBMECs, overexpression of lncC11orf54-1 promoted the phosphorylation of the NF-kB p65 subunit in a dose-dependent manner (Fig. 4a). As previously demonstrated, lncC11orf54-1 can be processed to mgU2-19 and mgU2-30 in E. coli-infected $\mathrm{hBMECs}$, therefore, we validated the potential regulatory effects of mgU2-19 or mgU2-30 on p65 phosphorylation. In agreement with the lncC11orf54-1 overexpression results, the overexpression of mgU2-30 in hBMECs also dose-dependently enhanced the phosphorylation level of p65, but mgU2-19 had no such effect (Fig. 4b and c).

To further confirm that mgU2-30 functions to activate the NF- $\mathrm{KB}$ pathway, we used CRISPR-Cas9 mediated genome editing in hBMECs to generate double-strand DNA breaks in the mgU2-30 region of lncC11orf54-1. Through screening for clones, we retained three clones in which the mgU2-30 region was deleted, and the PCR identification results for these deleted clones are shown in Fig. $4 \mathrm{~d}$ and e. The results showed that in E. coliinfected hBMECs, knockout of the mgU2-30 region of lncC11orf54-1 reduced the phosphorylation level of p65 (Fig. 4f). Collectively, these data indicate that the mgU230 fragment generated from lncC11orf54-1 facilitates the activation of the NF- $\mathrm{kB}$ pathway in the $E$. coli-induced inflammatory response of hBMECs.

\section{MgU2-30 promoted IRAK1 oligomerization and facilitated its auto-phosphorylation}

Although we have provided clues indicating that p65 is a key regulator of the mgU2-30-dependent inflammatory response, the details of the molecular mechanism by which mgU2-30 regulates p65 phosphorylation are unclear. Here, we performed RAP assay with biotinylated mgU2-30 probes, followed by immunoblotting, to characterize the mgU2-30-interacting proteins in hBMECs. The associated proteins were analyzed by SDS-PAGE with silver staining. We found that proteins around $60 \mathrm{kDa}$ may interact with mgU2-30 (Fig. 5a). Three key signaling proteins (IRAK1, p65, and TRAF6) with crucial functions in the activation of the canonical NF- $\mathrm{BB}$ pathway were identified by immunoblotting, and among them, IRAK1 was confirmed to bind to mgU2-30 (Fig. 5b). To further verify this interaction between IRAK1 and mgU2-30, we used RIP assay and found that the anti-IRAK1 antibody significantly enriched mgU2-30 (Fig. 5c). Moreover, RNA FISH combined with immunofluorescence demonstrated the colocalization of mgU2-30 and IRAK1 (Fig. 5d and Additional file 1: Fig. S1).

IRAK1 is a serine/threonine kinase that mediates the activation of NF- $\mathrm{KB}$ and MAPK pathways [23]. Its oligomerization and auto-phosphorylation are essential for signal transduction, resulting in IRAK1 activation and execution of the pathways [24, 25]. We subsequently determined whether the interaction of mgU2-30 with IRAK1 affected its oligomerization and phosphorylation, and cells were transfected to express Flag-tagged IRAK1 and his-tagged IRAK1, with or without the presence of mgU2-30 overexpression constructs. Co-immunoprecipitation assays demonstrated that IRAK1 was able to interact with itself (Fig. 6a), and this oligomerization of IRAK1 could be promoted by mgU2-30 (Fig. 6b). To determine the effects of the lncC11orf54-1-derived mgU2-30 fragment on the phosphorylation of IRAK1, hBMECs were transfected with a gradient of lncC11orf54-1 overexpression constructs, as shown in Fig. 6c and d. These experiments revealed that overexpression of $\operatorname{lnc} \mathrm{C} 11$ orf54-1

\footnotetext{
(See figure on next page.)

Fig. 4 MgU2-30 promotes meningitic E. coli-induced activation of NF-kB signaling. A Western blot analysis of NF-kB p65 and phosphorylated p65 in hBMECs transfected with multiple dosages of IncC1 1 orf54-1 (0, 100,500, 1000, and 20,000 ng) under E. coli infection. $\beta$-actin was used as the loading control. B hBMECs were transfected with control construct (pcDNA3.1), overexpression constructs of IncC11 orf54-1, mgU2-19, or mgU2-30, and infected with E. coli; the protein levels of NF-KB p65 and phosphorylated p65 were determined by Western blotting. $\beta$-actin was used as the loading control. C Western blot analysis of NF-KB p65 and phosphorylated p65 in hBMECs transfected with multiple dosages of mgU2-30 $(0,100,500,1000$, and $2000 \mathrm{ng})$ under E. coli infection. $\beta$-actin was used as the loading control. D Schematic diagram of CRISPR/Cas9 knockout strategies at the mgU2-30 loci. A deletion of $48 \mathrm{bp}$ was validated by sequencing. The red rectangle outlines the deletion region, the blue arrows indicate genotyping PCR primers for identifying knocked-out cell clones. $\mathbf{E}$ Gel image shows PCR identification results for wildtype hBMECs, and mgU2-30 knockout hBMECs. F Effects of mgU2-30 knock out on the expression of NF-kB p65 and phosphorylated p65 in E. coli treated hBMECs, as determined by Western blotting. $\beta$-actin was used as the loading control
} 


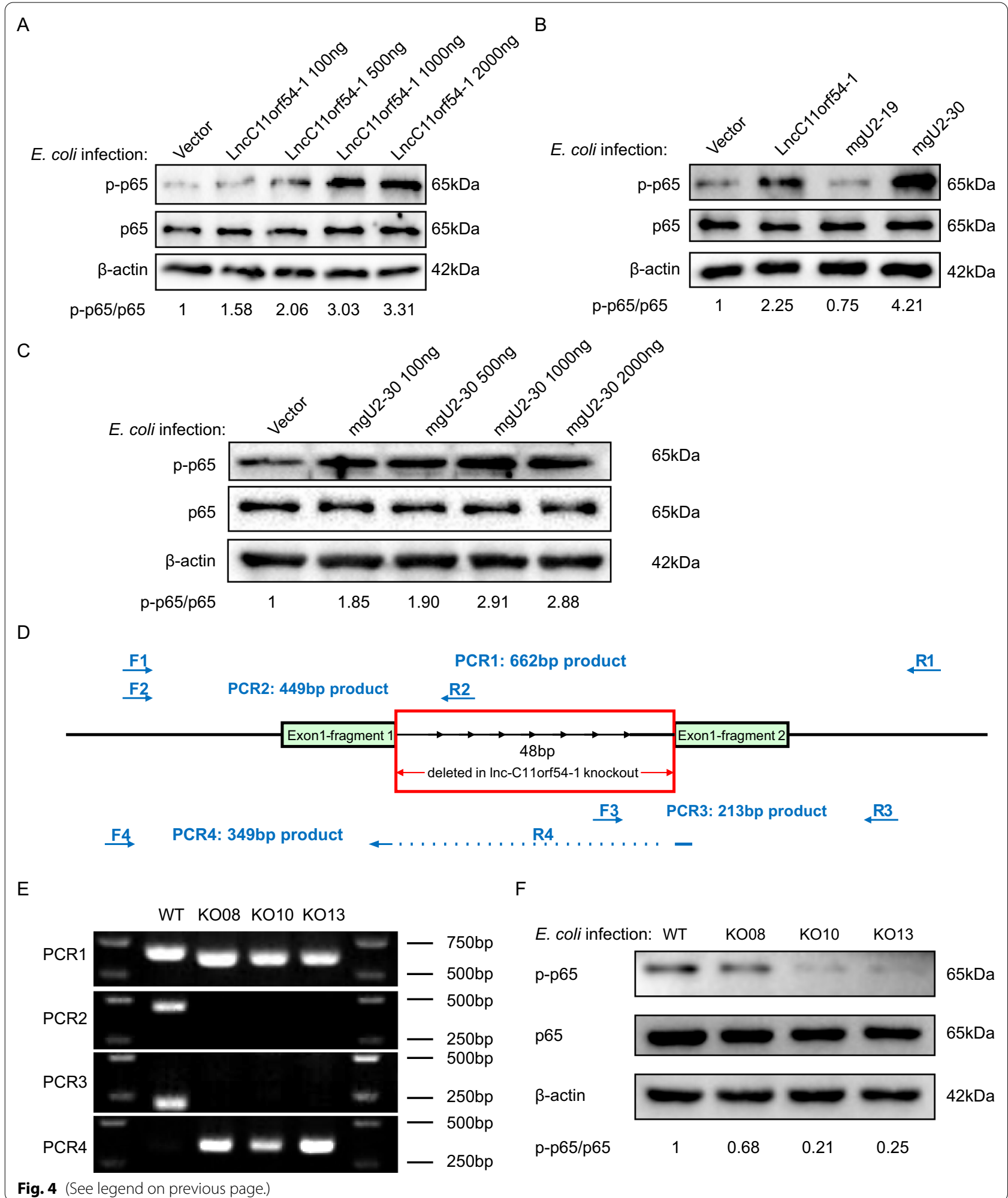

in E. coli-challenged hBMECs promoted the phosphorylation of IRAK1 in a dose-dependent manner, and mgU2-30 also dose-dependently facilitated IRAK1 phosphorylation. Altogether, these data suggest that mgU2-30 generated from lncC11orf54-1 interacts with 


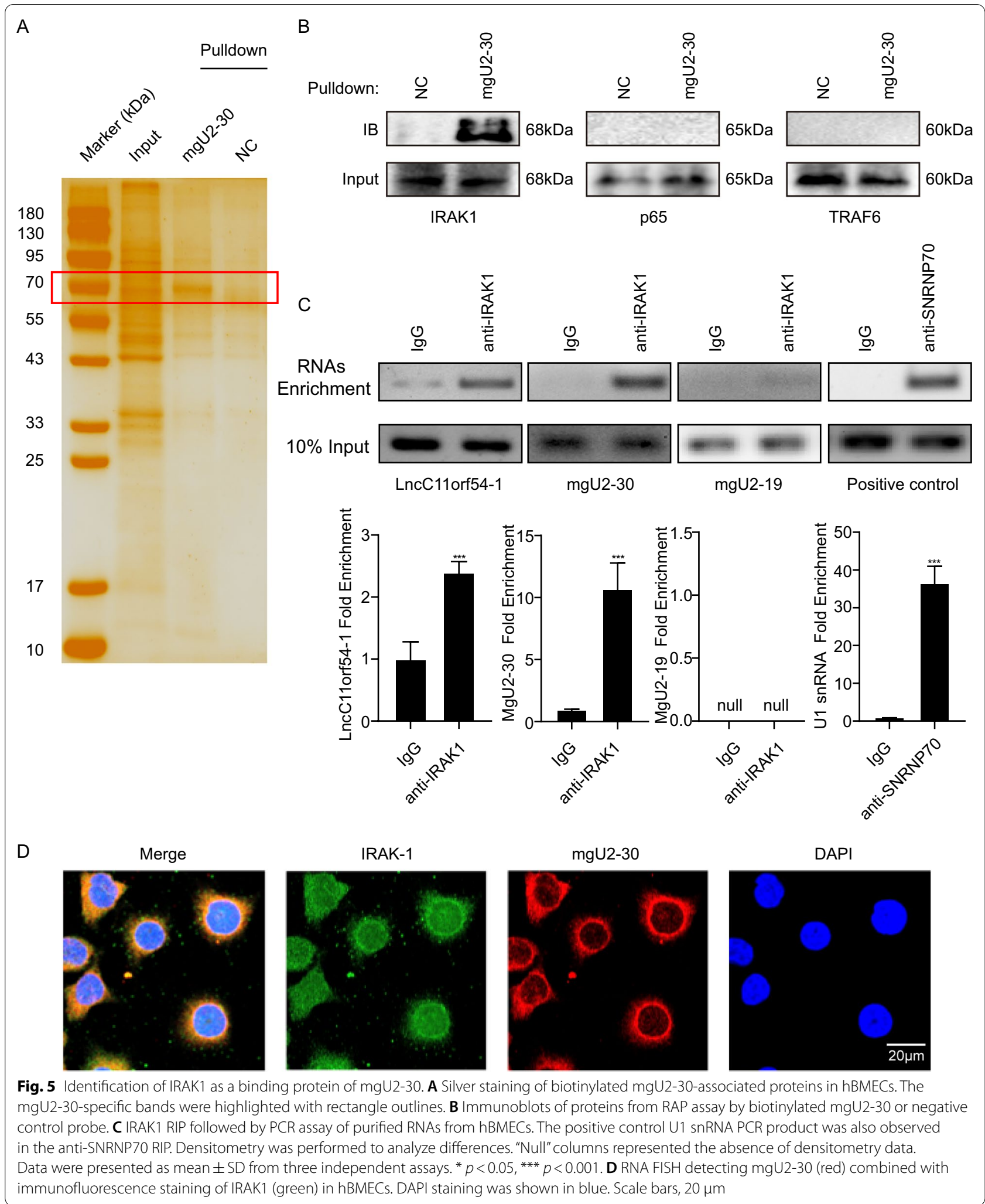




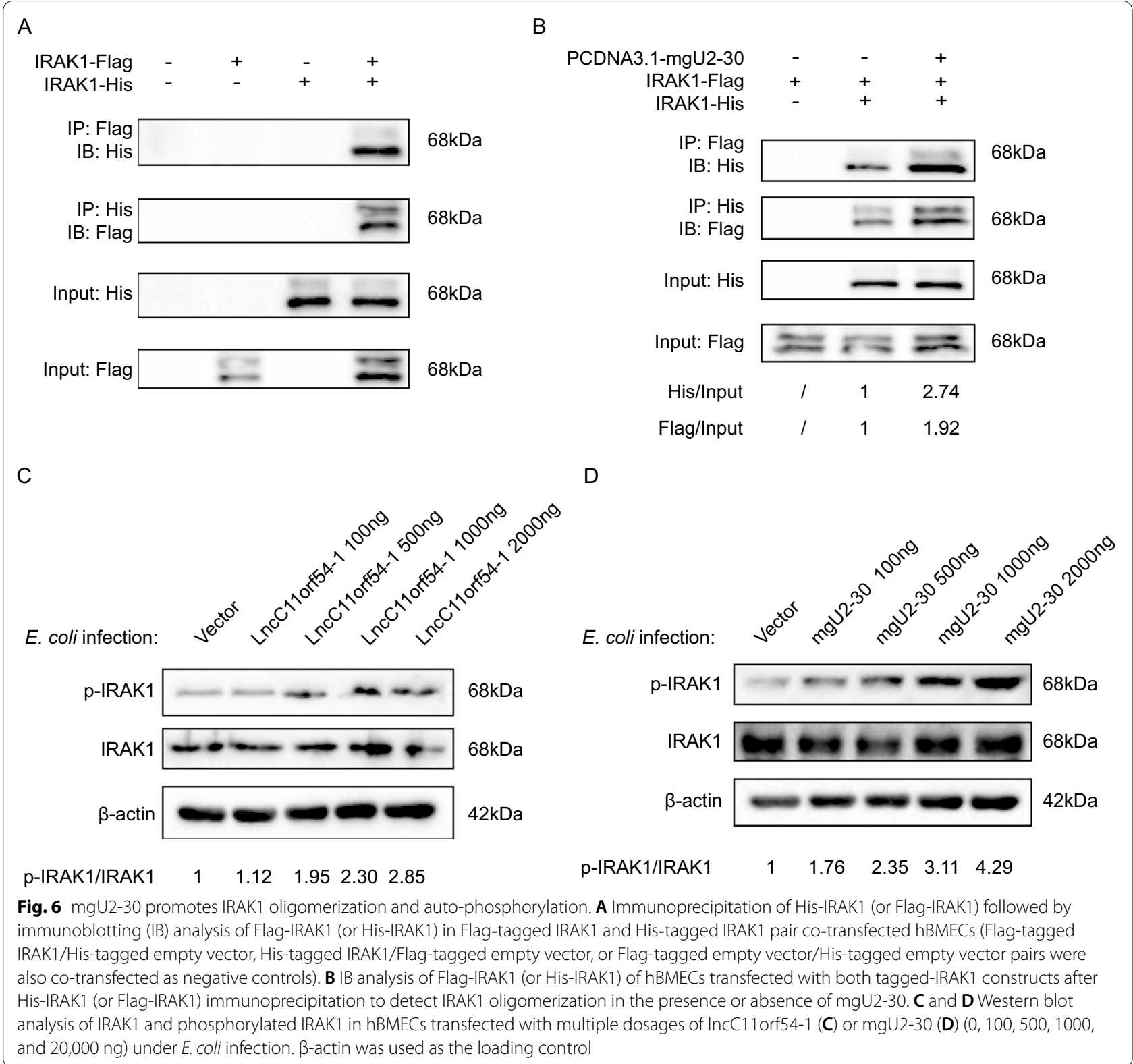

IRAK1 to promote its oligomerization, which eventually leads to the auto-phosphorylation of IRAK1.

\section{MgU2-30 promoted E. coli-induced inflammatory responses in hBMECs}

We further determined the effects of mgU2-30 in hBMECs by overexpressing or knocking out mgU2-30, which were subsequently infected with or without $E$. coli. At $3 \mathrm{~h}$ after $E$. coli infection, the qPCR results showed that overexpression of mgU2-30 led to a significant increase in the levels of pro-inflammatory cytokines IL- 6 , TNF- $\alpha$, and IL-1 $\beta$, whereas knockout of mgU2-30 did not cause an increase in the level of these cytokines in hBMECs (Fig. 7a and c). Consistent with the qPCR results, Western blot analysis indicated that mgU2-30 overexpression promoted the expression of pro-inflammatory cytokines in hBMECs under E. coli challenge (Fig. 7b). In contrast, the knockout of mgU2-30 in hBMECs no longer caused such a significant increase of these cytokines (Fig. 7d). Moreover, simple overexpression or knockout of mgU230 without $E$. coli infection did not result in a change in pro-inflammatory cytokines at either the transcriptional and protein levels (Fig. 7a-d). Taken together, these findings suggest that mgU2-30 can effectively facilitate the 


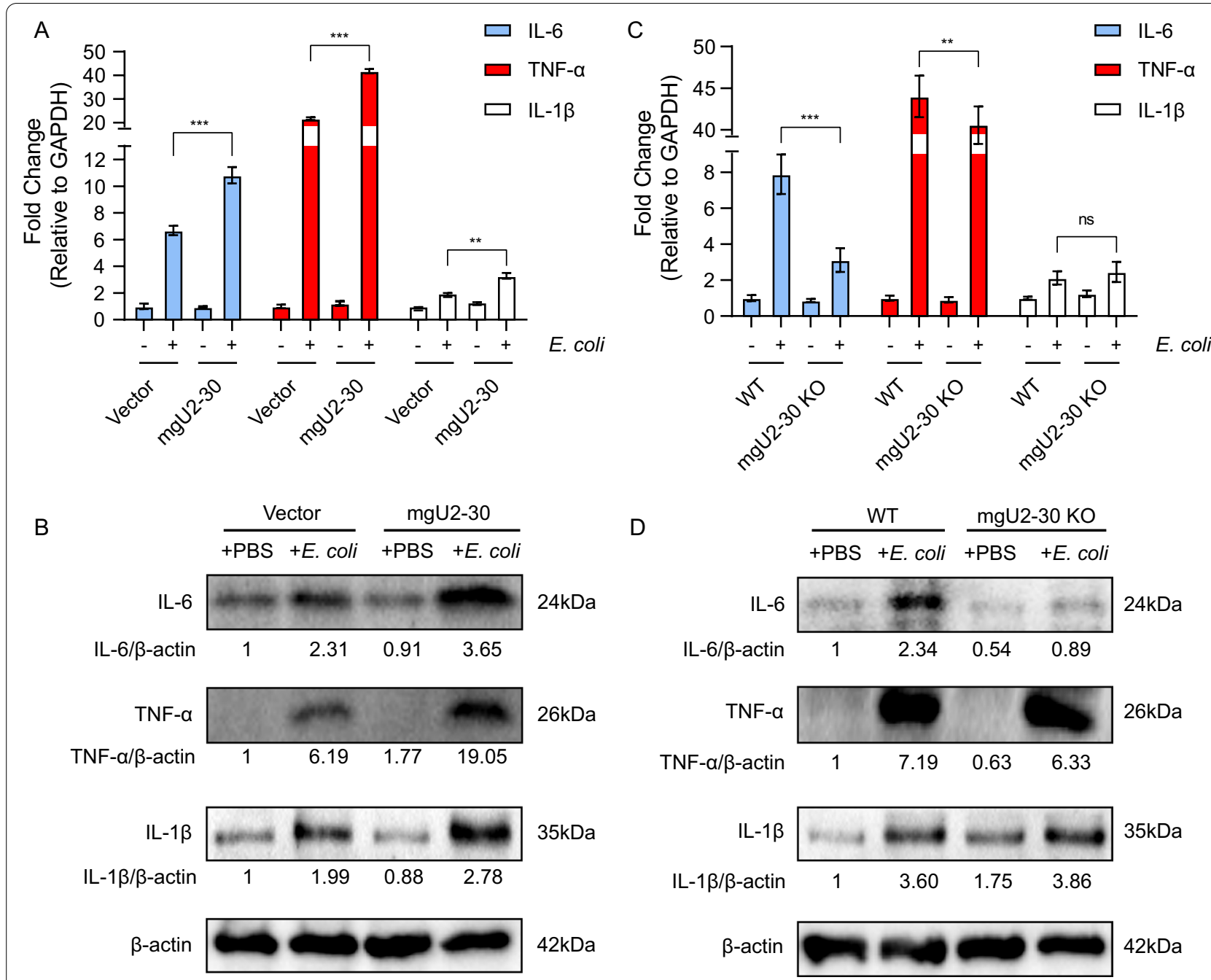

Fig. 7 mgU2-30 augments the meningitic E. coli-induced inflammatory response in hBMECs. A Effects of mgU2-30 overexpression on the expression of inflammatory factors in hBMECs, determined by qPCR. GAPDH was used as the internal reference. Mean $\pm S D$ were shown, $n=3$. ${ }^{* *} p<0.01$, and ${ }^{* *} p<0.001$ by the student's t-test. $\mathbf{B}$ Effects of mgU2-30 overexpression on the expression of inflammatory factors in hBMECs, as determined by Western blotting. $\beta$-actin was used as the loading control. C Effects of mgU2-30 knockout on the expression of inflammatory factors in hBMECs, determined by qPCR. GAPDH was used as the internal reference. Mean \pm SD were shown, $n=3 .{ }^{* *} p<0.01$, and ${ }^{* * *} p<0.001$ by the t-test. D Effects of mgU2-30 knockout on the expression of inflammatory factors in hBMECs, as determined by Western blotting. $\beta$-actin was used as the loading control

expression of pro-inflammatory cytokines in meningitic E. coli-infected hBMECs and eventually aggravate the inflammatory response of hBMECs.

\section{Discussion}

Accumulating evidence has suggested that lncRNAs are involved in inflammatory processes $[16,26,27]$ and in regulating CNS-related diseases, such as ischemic stroke, multiple sclerosis, and Huntington's disease [28-30]. However, the roles of lncRNAs in CNS infectious diseases remain poorly understood. In this study, we reanalyzed lncRNA expression profiles in response to meningitic $E$. coli challenge in hBMECs and characterized a differentially expressed lncRNA, lncC11orf54-1. E. coli infection led to the processing of lncC11orf54-1 into mgU2-30, which effectively augmented the infection-caused inflammatory responses by facilitating the oligomerization and autophosphorylation of IRAK1 (Fig. 8).

In the past decade, IncRNAs have been increasingly recognized as regulators of diverse pathological processes, such as cancer, chronic inflammation, and infectious diseases [31,32]. Studies have indicated that lncRNAs play regulatory roles in the epigenetic, transcriptional, post-transcriptional, and translational 


\section{Extracellular}

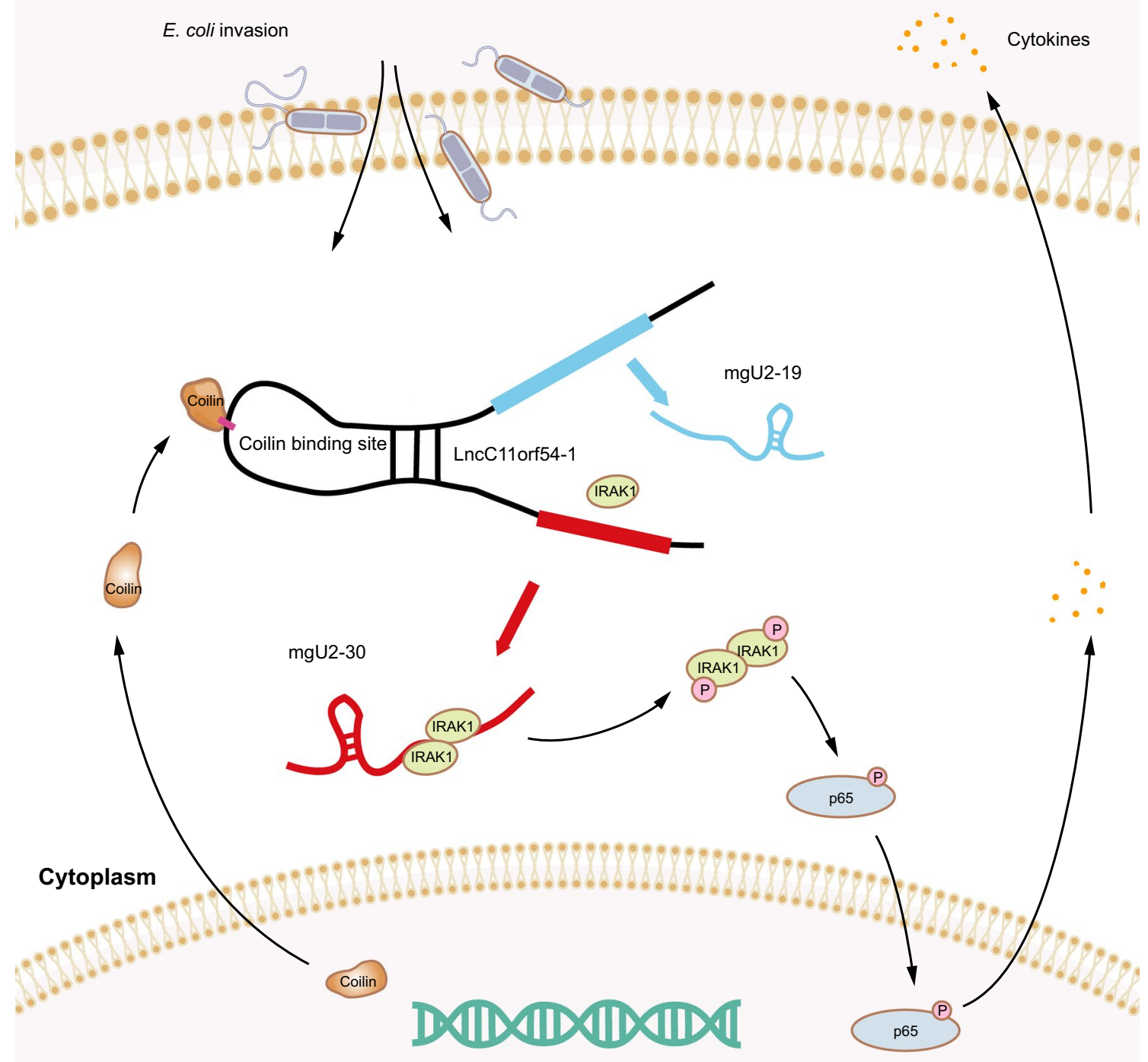

Nucleus

Fig. 8 Schematic of the molecular mechanism of IncC11 orf54-1 in meningitic E. coli-triggered inflammatory responses. Meningitic E. coli infection of hBMECs induces the degradation of IncC11 orf54-1 and the production of mgU2-30, while mgU2-30 facilitates the oligomerization and phosphorylation of IRAK1, subsequently promoting the inflammatory responses

levels and in post-translational modifications [33-35]. Among these, the most reported regulatory mechanism is the action of IncRNAs as competitive endogenous RNAs to competitively sponge miRNAs, thus resulting in decreased mRNA degradation [36]. Over 3000 studies have reported that lncRNAs function as sponges to interact with miRNAs; for example, lncRNA ZFAS1 can sponge miR-150-5p to upregulate VEGFA expression to contribute to the progression of colorectal cancer [37], yet other regulatory mechanisms of lncRNAs are 
few reported. Our study aimed to uncover the functional lncRNAs involved in human vascular inflammation via a unique mechanism. In $E$. coli-challenged hBMECs, we filtered out lncRNAs with high abundance, which might suggest certain potential biological function. In addition, before finally focusing on lncC11orf54-1, a major of these lncRNAs were overexpressed in hBMECs and this lncRNAs-overexpression screen revealed that lncC11orf54-1 contributed to NF- $\mathrm{kB}$ p65 subunit phosphorylation during $\mathrm{E}$. coli infection. We therefore considered lncC11orf54-1 as an effective regulator of inflammatory responses in meningitic $E$. coli-induced neuroinflammation.

LncC11orf54-1 is an intronic lncRNA, also known as SCARNA9, which contains two smaller fragments, mgU2-19 and mgU2-30 and a GU-rich motif between them. Various studies have demonstrated that in vitro transcribed lncC11orf54-1 can be processed to generate mgU2-19 and mgU2-30 by co-incubating with the purified protein coilin [22, 38, 39]. Coilin is a Cajal body marker protein with RNase activity and is generally located in the nucleus. Coilin is occasionally motile; it can make large movements and traverse the full diameter of the nucleus in some cases, such as in cell division [40, 41]. Since previous studies have already shown that coilin can target RNAs with GU-rich motif and degrade them, we further demonstrated that in our hBMECs model, $E$. coli led to the translocation of coilin from the nucleus to the cytoplasm, thus providing the opportunity for coilin to degrade cytoplasmic lncC11orf54-1. And actually, it was observed that lncC11orf54-1 was indeed degraded.

The NF-кB pathway is considered a central mediator of the immune response, and most bacteria can activate the NF-kB pathway. For example, E. coli K1 IbeA-binding proteins Vimentin and PTB-associated splicing factor act in concert to activate NF- $\mathrm{B}$ [9], while Streptococcus pneumoniae can activate NF-kB by triggering the host factors toll-like receptors 2 and 4 [42]. However, the function of host lncRNAs in activating the NF- $\mathrm{kB}$ pathway during bacterial infection is poorly understood. We, thus, indicated that lncRNA lncC11 orf54-1 is involved in the phosphorylation of $\mathrm{p} 65$, which indicates activation of the NF- $\mathrm{kB}$ pathway. There are at least two pathways of NF- $\mathrm{KB}$ activation. The canonical pathway relies on IKK $\gamma$-IKK $\beta$-mediated degradation of the NF- $\kappa B$ inhibitor alpha $(\mathrm{I} \kappa \mathrm{B} \alpha)$. The alternative pathway relies on IKK $\alpha$-mediated p100 phosphorylation and processing to $\mathrm{p} 52[43,44]$. Among them, IRAK1 is a key signal transducer [25], which can be recruited by myeloid differentiation marker 88 (MyD88) and leads to the phosphorylation of IRAK1 and IRAK4 [45]. Phosphorylation of IRAK1 and IRAK4 facilitates oligomerization and auto-ubiquitination of
TRAF6 [46], which is followed by the activation of IKK, and ultimately leads to the activation of NF- $\mathrm{KB}$ [47]. A few studies have reported that lncRNAs can influence the modification of these signaling molecules and affect the activation of the NF- $\kappa B$ pathway. For example, lncRNA Mirt2 inhibits the activation of NF-kB and MAPK pathways by attenuating the K63 ubiquitination of TRAF6 in macrophages [16]. In contrast, our results revealed that the product of 1 ncC 11 orf 54 processed by coilin could enrich IRAK1. Since it is generally believed that IRAK1 undergoes oligomerization and autophosphorylation, we subsequently demonstrated that the oligomerization and autophosphorylation of IRAK1 could be promoted by enrichment of mgU2-30, thereby facilitating the activation of the NF- $\mathrm{kB}$ pathway.

Inflammation is a fastidiously balanced condition orchestrated by cytokines, chemokines, and their respective receptors [48]. In bacterial meningitis, bacterial invasion across the BBB stimulates BMECs, pericytes, astrocytes, and microglia to release a variety of inflammatory factors, including cytokines and chemokines, resulting in severe CNS inflammatory responses $[8,49,50]$. In the current study, we found that mgU2-30 potentiated the release of the proinflammatory cytokines IL- 6 , TNF- $\alpha$, and IL- $1 \beta$, which represented a potential relationship between mgU2-30 and the neuroinflammatory response. Taken together, our findings provide substantial evidence on the proinflammatory function of lncRNAs during meningitiscausing bacterial infection. In meningitic E. coli-treated hBMECs, we demonstrated that mgU2-30 derived from lncC11orf54-1 could function as a reservoir to enrich IRAK1, which facilitated the oligomerization and auto-phosphorylation of IRAK1 and, therefore, the phosphorylation of p65. Activation of p65 eventually potentiates vascular inflammation. However, inflammation is a complicated and dynamic process, and our in vitro hBMECs model could only partially resemble in vivo conditions, and the effects of different factors on meningitic $E$. coli-induced inflammatory responses should be considered. In addition, further studies are required to explore the mechanisms of coilin translocation caused by $E$. coli infection.

In conclusion, we characterized the function of lncRNA lncC11orf54-1 in meningitic E. coli-infected hBMECs and investigated its possible working mechanism. Our data confirmed that E. coli infection in hBMECs induced the translocation of coilin, which led to the processing of lncC11 orf54-1 into mgU2-30. MgU2-30 in hBMECs specifically facilitated the phosphorylation of IRAK1, thus potentiating inflammatory responses by activating NF-kB (Fig. 8). These findings suggest that lncC11orf54-1 and mgU2-30 may serve as novel targets for 
future therapeutic strategies against bacterial meningitis. Moreover, the translocation of coilin from the nucleus to the cytoplasm may be a potential target for the diagnosis of inflammation.

\section{Materials and methods}

\section{Cell line and cell culture}

The hBMECs cell line was kindly provided by Prof. Kwang Sik Kim from Johns Hopkins University School of Medicine. It was routinely cultured in RPMI1640 media with $10 \%$ fetal bovine serum, $2 \mathrm{mM}$ L-glutamine, $1 \mathrm{mM}$ sodium pyruvate, essential amino acids, non-essential amino acids, vitamins, and penicillin and streptomycin $(100 \mathrm{U} / \mathrm{mL})$ in a $37{ }^{\circ} \mathrm{C}$ incubator under $5 \% \mathrm{CO}_{2}$ until the cell monolayer reached confluence.

\section{Meningitic $E$. coli infection of hBMECs}

The meningitic E. coli strain PCN033, a highly virulent cerebrospinal fluid isolate isolated in China in 2006, was used as the model [51]. Bacterial cells were routinely grown in Luria-Bertani medium at $37{ }^{\circ} \mathrm{C}$ overnight. hBMECs were challenged with E. coli PCN033 as follows. An overnight E. coli culture was resuspended and diluted in serum-free medium and then added to the starved confluent hBMECs monolayer at a multiplicity of infection (MOI) of 10 (approximately $10^{7}$ colony-forming units per $\mathrm{mL}$ ) and incubated at $37{ }^{\circ} \mathrm{C}$ with $5 \% \mathrm{CO}_{2}$ for $3 \mathrm{~h}$.

\section{Transfection}

hBMECs were cultured in six-well plates and grown to 50-60\% confluence. Cells were subsequently transfected with the constructs using the jetPRIME transfection reagent (Polyplus transfection, Illkirch, France), according to the manufacturer's instructions. Briefly, $200 \mu \mathrm{L}$ of jetPRIME buffer was added to the $2000 \mathrm{ng}$ of plasmids before adding $4 \mu \mathrm{L}$ of jetPRIME. The suspension was briefly mixed by vortexing, incubated at $25^{\circ} \mathrm{C}$ for $10 \mathrm{~min}$, and then added dropwise to the cells and cultured at $37{ }^{\circ} \mathrm{C}$ with $5 \% \mathrm{CO}_{2}$ for $48 \mathrm{~h}$.

\section{RNA isolation and quantitative real-time polymerase chain reaction analysis}

hBMECs were washed three times with ice-cold phosphate-buffered saline (PBS) before RNA extraction. Total RNA was extracted from hBMECs using TRIzol reagent (Invitrogen, Carlsbad, CA, USA) according to the manufacturer's protocol. After RNA extraction, $500 \mathrm{ng}$ of total RNA was reverse transcribed into cDNA using HiScript II Q RT SuperMix (Vazyme, Nanjing, China). Quantitative real-time polymerase chain reaction (qPCR) was performed using a qTOWER3/G qPCR thermal cycler
(Analytikjena, Jena, Germany) with the AceQ qPCR SYBR Green Master Mix (Vazyme), according to the manufacturer's instructions. The amplification conditions were as follows: $50{ }^{\circ} \mathrm{C}$ for $2 \mathrm{~min}, 95{ }^{\circ} \mathrm{C}$ for $10 \mathrm{~min}$, followed by 40 cycles of $95{ }^{\circ} \mathrm{C}$ for $15 \mathrm{~s}$ and $60{ }^{\circ} \mathrm{C}$ for $1 \mathrm{~min}$. The products were then subjected to a melting curve stage comprising denaturation at $95{ }^{\circ} \mathrm{C}$ for $15 \mathrm{~s}$, annealing at $60^{\circ} \mathrm{C}$ for $1 \mathrm{~min}$, and slow dissociation by ramping from $60{ }^{\circ} \mathrm{C}$ to $95{ }^{\circ} \mathrm{C}$ at $0.1{ }^{\circ} \mathrm{C} / \mathrm{s}$ to ensure the specificity of the primers for their target sequences. The relative gene expression was normalized to that of glyceraldehyde 3-phosphate dehydrogenase (GAPDH). The primers used for qPCR are listed in Additional file 1: Table S1. Each assay was performed in triplicates.

\section{RNA fluorescence in situ hybridization and protein immunofluorescence}

For RNA fluorescence in situ hybridization (FISH), a commercial FISH kit was purchased from Bersinbio (Guangzhou, China) and used according to the manufacturer's instructions. Briefly, hBMECs grown on 20-mm cell culture dishes (SORFA, Huzhou, China) were fixed in $4 \%$ paraformaldehyde for $30 \mathrm{~min}$ and washed twice with DNase/RNase-free PBS. Cells were permeabilized with $0.1 \%$ Triton $\mathrm{X}-100$ for $15 \mathrm{~min}$, washed twice with PBS, and then treated with $2 \times$ saline sodium citrate (SSC). These samples were subsequently treated as follows: $70 \%$ ethanol for $5 \mathrm{~min}, 85 \%$ ethanol for $5 \mathrm{~min}$, and $100 \%$ ethanol for $5 \mathrm{~min}$. Dried samples were then incubated with pre-hybridization buffer $(2 \times$ SSC, $10 \%$ formamide) at $37{ }^{\circ} \mathrm{C}$ for $30 \mathrm{~min}$, followed by incubation in the hybridization buffer with probes for lncC11 orf54-1 (5'-Cy3-CCACCCTCAATCTCATTCAT-3') and mgU230 (5'-Cy3-AGCTCAGGTCAAGTGTAGAA- $\left.3^{\prime}\right)$ to a final concentration of $100 \mathrm{nM}$ at $37{ }^{\circ} \mathrm{C}$ overnight. The samples were then washed with SSC buffer. All probes were purchased from GenePharma (Shanghai, China). For colocalization analysis of RNA and protein, the RNA FISH protocol was combined with protein immunofluorescence. Samples were treated with blocking buffer and then incubated for $2 \mathrm{~h}$ with primary antibodies against IRAK1 (Sigma-Aldrich, St. Louis, MO, USA) or coilin (Proteintech, Chicago, IL, USA), followed by fluorescein isothiocyanate-conjugated goat anti-mouse or anti-rabbit secondary antibody (Biodragon, Beijing, China). Nuclei were counterstained with 4',6-diamidino-2-phenylindole (Beijing Solarbio Science \& Technology Co., Ltd., Beijing, China). Images were acquired using a confocal microscope (LSM710, Carl Zeiss, Oberkochen, Germany).

\section{Northern blotting}

The hBMECs were infected with meningitic E. coli, followed by RNA isolation. Fifty micrograms of RNA from 
each sample were run on $1.5 \%$ formaldehyde agarose gel in 5×3-morpholinopropane-1-sulfonic acid buffer at $50 \mathrm{~V}$ for $60 \mathrm{~min}$. The gel was then washed in diethyl pyrocarbonate-treated $\mathrm{H}_{2} \mathrm{O}$ and $10 \times \mathrm{SSC}$ and transferred onto a positively charged nylon membrane by siphoning. After transfer, the membrane was rinsed quickly in distilled water and allowed to dry. The RNA was then crosslinked to the membrane using an ultraviolet cross-linker (UVP, Upland, CA, USA) at a setting of $120,000 \mu \mathrm{J} / \mathrm{cm}^{2}$. The membrane was placed in a hybridization bottle and pre-hybridized using Ultrahyb Ultrasensitive Hybridization buffer (Ambion Life Technologies, Grand Island, NY, USA) at $42{ }^{\circ} \mathrm{C}$ for $1.5 \mathrm{~h}$. The digoxigenin (DIG)-labeled probe for mgU2-30 (5'-DIG-AGCTCAGGTCAAGTG TAGAA-3') was purchased from Genscript (Nanjing, China). After pre-hybridization, the membrane was hybridized with Ultrahyb Ultrasensitive Hybridization buffer containing a probe at $42{ }^{\circ} \mathrm{C}$ overnight in a slow rotating hybridization oven. The blots were then washed with $2 \times$ SSC/0.1\% sodium dodecyl sulfate (SDS) and $0.5 \times \mathrm{SSC} / 0.1 \%$ SDS and detected using the DIG Nucleic Acid Detection Kit (Roche, Basel, Switzerland) according to the manufacturer's instructions.

\section{Western blotting}

hBMECs were lysed using radioimmunoprecipitation assay buffer (Epizyme, Shanghai, China) with protease inhibitor cocktail and phosphatase inhibitor cocktail (MedChemExpress, Monmouth, NJ, USA), followed by centrifugation at $12,000 \mathrm{rpm}$ for $15 \mathrm{~min}$ at $4{ }^{\circ} \mathrm{C}$ to remove insoluble cell debris. The supernatants were measured using the bicinchoninic acid protein assay kit (NCM Biotech, Suzhou, China) and used for western blot analyses. Equal amounts of protein were separated by $12 \%$ SDS-polyacrylamide gel electrophoresis (PAGE) and transferred to polyvinylidene difluoride membranes. Membranes were blocked with $5 \%$ bovine serum albumin in Tris-buffered saline with Tween 20, followed by immunoblotting with primary antibodies against coilin, GAPDH, lamin B, $\beta$-actin, IL-6, tumor necrosis factor- $\alpha$ (TNF- $\alpha$ ), IL-1 $\beta$, His, Flag (Proteintech, Chicago, IL, USA), IRAK1, TNF receptor-associated factor 6 (TRAF6) (Merck Millipore, Billerica, MA, USA), NF-kB p65, phospho-NF-kB p65 (Cell Signaling Technology, Danvers, MA, USA), or phospho-IRAK1 (Abcam, Cambridge, MA, USA). Membranes were then washed and incubated with horseradish peroxidase-conjugated antirabbit or anti-mouse secondary antibodies (Biodragon, Beijing, China). The blots were visualized with the Super electrochemiluminescence Prime kit (US Everbright, Suzhou, China) and densitometrically analyzed using Image Lab software (Bio-Rad, Hercules, CA, USA).

\section{RNA immunoprecipitation}

The RNA immunoprecipitation (RIP) assay was performed using the Magna RIP RNA-Binding Protein Immunoprecipitation Kit (Merck Millipore, Billerica, MA, USA), according to the manufacturer's instructions. Briefly, protein A/G magnetic beads were incubated with anti-IRAK1 antibody, SNRNP70 antibody (positive control), or mouse IgG (negative control), and rotated for $30 \mathrm{~min}$ at room temperature. Antibody-treated magnetic beads were then co-incubated with hBMECs lysates and rotated overnight at $4{ }^{\circ} \mathrm{C}$, followed by digestion with proteinase $\mathrm{K}$ buffer and purification of RNA. The purified RNA was further quantified and reverse transcribed into cDNA. The abundance of target genes was determined by qPCR.

\section{RNA antisense purification}

The RNA antisense purification (RAP) assay was performed using the RNA Antisense Purification Kit (BersinBio, Guangzhou, China) according to the manufacturer's instructions. Briefly, hBMECs were crosslinked and homogenized in the presence of protease and RNase inhibitors, and DNA was subsequently removed using DNase. Samples were denatured and incubated with biotin-labeled probes for mgU2-30 (5'-Biotin-AGC TCAGGTCAAGTGTAGAA- $3^{\prime}$ ) or negative control probe with rotation for $180 \mathrm{~min}$ at $37{ }^{\circ} \mathrm{C}$, followed by addition of streptavidin beads with rotation for $30 \mathrm{~min}$ at room temperature. Finally, the protein bound to the beads was dissociated using elution buffer and analyzed by immunoblot assay.

\section{Deletion of mgU2-30 in hBMECs via CRISPR/Cas9 technology}

A three-in-one pYSY-spCas9-sgRNA-Puro vector was obtained from YSY Biotech (Nanjing, China). Human mgU2-30-sgRNA1 (5'- CACCGACTGATCTTTGTA ACTATGA-3') and sgRNA2 (5'- AAACAATCATTT CTGGGCAATGATC-3') were synthesized and cloned into the vector to generate the pYSY-spCas9-mgU230-sgRNA-Puro construct. hBMECs were seeded into six-well plates at a density of $2 \times 10^{5}$ cells per well for $24 \mathrm{~h}$, followed by transient transfection with $2 \mu \mathrm{g}$ of pYSY-spCas9-mgU2-30-sgRNA-Puro plasmid using the jetPRIME transfection reagent. The cells were incubated at $37{ }^{\circ} \mathrm{C}$ with $5 \% \mathrm{CO}_{2}$ for $24 \mathrm{~h}$, and a fresh medium containing $200 \mathrm{ng} / \mathrm{mL}$ puromycin was added and incubated for another $48 \mathrm{~h}$. Cells were then collected, and each single-cell clone was transferred into 96-well plates following a limiting dilution method. Genomic DNA was extracted when the cells were confluent using QuickExtract DNA Extraction Solution (YSY Biotech). Cells with mgU2-30 sequence deletion 
were validated by PCR using GoldenStar T6 Super PCR Mix (Tsingke Biological Technology, Beijing, China), as shown in Fig. 4d. The primers used for identification were as follows: $5^{\prime}$-TTATGCTGTGGAGGAAGA $-3^{\prime}$ (forward) and $5^{\prime}$-ACTGGGAGCCTTTTAAGT-3' (reverse) (amplicon PCR1), 5'-TGTGGAGGAAGAACA TGC-3' (forward) and 5'-TTCATCATTGCCCAGAAA $-3^{\prime}$ (reverse) (amplicon PCR2), 5'-GGGCAATGATGA AAAGGT-3' (forward) and 5'AGGCTCCCAGTGGAA ACA-3' (amplicon PCR3), and 5'-AGCTGTTTGGCT TCGTAT- $3^{\prime}$ (forward) and $5^{\prime}$-CCATCAATTAGGCTT TCA-3' (reverse) (amplicon PCR4).

\section{Statistical analysis}

Data are expressed as mean \pm SD from three independent experiments, and the significance of differences between groups was evaluated using the t-test. " $\mathrm{p}<0.05$ was considered significant, and $* \mathrm{p}<0.01$ and $* * \mathrm{p}<0.001$ were considered extremely significant. Graphs were plotted and analyzed using GraphPad Prism (version 6.0; GraphPad Software, La Jolla, CA, USA).

\begin{abstract}
Abbreviations
BBB: Blood-brain barrier; BMEC: Brain microvascular endothelial cell; CNS: Central nervous system; DIG: Digoxigenin; FISH: Fluorescence in situ hybridization; GAPDH: Glyceraldehyde 3-phosphate dehydrogenase; hBMEC: Human brain microvascular endothelial cell; LL: Interleukin; IRAK: Interleukin-1 receptorassociated kinase; LncRNA: Long non-coding RNA; MAPK: Mitogen-activated protein kinase; NF-KB: Nuclear factor kappa B; PBS: Phosphate-buffered saline; PAGE: Polyacrylamide gel electrophoresis; GPCR: Quantitative real-time polymerase chain reaction; RAP: RNA antisense purification; RIP: RNA immunoprecipitation; SDS: Sodium dodecyl sulfate; SSC: Saline sodium citrate; TNF: Tumor necrosis factor.
\end{abstract}

\section{Supplementary Information}

The online version contains supplementary material available at https://doi. org/10.1186/s13041-021-00890-8.

Additional file 1: Table S1. Primers used for qPCR. Fig. S1. Colocalization analysis of mgU2-30 and IRAK1. Quantitative analysis of mgU2-30 and IRAK1 colocalization by Pearson's correlation and Manders' (M1 and M2) colocalization coefficients. Data were presented as mean \pm SD from five independent analyses.

\section{Acknowledgements}

We would like to thank Prof. Kwang Sik Kim at Johns Hopkins University School of Medicine for providing the hBMECs cells.

\section{Authors' contributions}

$X W, B X$, and ZP designed the study, performed the experiments, and drafted the manuscript. $B X, R Y, D H$, and $L L$ analyzed and interpreted the data. $C T$ and $\mathrm{HC}$ provided technical support. JF, JC, XQ, ZP and XW revised the manuscript. All authors read and approved the final manuscript.

\section{Funding}

This work was supported by the National Key Research and Development Program of China (2021 YFD1800405), the National Natural Science Foundation of China, China (No. 31902241, 31772736, 32122086), the China Agriculture
Research System of MOF and MARA, Hubei Postdoctoral Preferential Foundation, China (590320102), and China Postdoctoral Science Foundation, China (2020M672379, 2021T140242).

\section{Availability of data and materials}

Data supporting the conclusions of this article are presented in this manuscript or Additional file 1.

\section{Declarations}

Ethics approval and consent to participate

Not applicable.

\section{Consent for publication}

Not applicable.

\section{Competing interests}

The authors declare that they have no competing interests.

\section{Author details}

${ }^{1}$ State Key Laboratory of Agricultural Microbiology, College of Veterinary Medicine, Huazhong Agricultural University, Wuhan, Hubei, China. ${ }^{2}$ Key Laboratory of Preventive Veterinary Medicine in Hubei Province, The Cooperative Innovation Center for Sustainable Pig Production, Wuhan, Hubei, China. ${ }^{3}$ Key Laboratory of Development of Veterinary Diagnostic Products, Ministry of Agriculture of the People's Republic of China, Wuhan, Hubei, China. ${ }^{4}$ International Research Center for Animal Disease, Ministry of Science and Technology of the People's Republic of China, Wuhan, Hubei, China.

Received: 18 September 2021 Accepted: 20 December 2021 Published online: 03 January 2022

\section{References}

1. Kim KS. Mechanisms of microbial traversal of the blood-brain barrier. Nat Rev Microbiol. 2008;6(8):625-34

2. Kim KS. Escherichia coli translocation at the blood-brain barrier. Infect Immun. 2001;69(9):5217-22.

3. Xie Y, Kim KJ, Kim KS. Current concepts on Escherichia coli K1 translocation of the blood-brain barrier. FEMS Immunol Med Microbiol. 2004:42(3):271-9.

4. Wang X, Maruvada R, Morris AJ, Liu JO, Wolfgang MJ, Baek DJ, et al. Sphingosine 1-phosphate activation of EGFR as a novel target for meningitic Escherichia coli penetration of the blood-brain barrier. PLoS Pathog. 2016;12(10):e1005926.

5. Kim KS. Pathogenesis of bacterial meningitis: from bacteraemia to neuronal injury. Nat Rev Neurosci. 2003;4(5):376-85.

6. Fu J, Li L, Yang X, Yang R, Amjad N, Liu L, et al. Transactivated epidermal growth factor receptor recruitment of alpha-actinin-4 from F-actin contributes to invasion of brain microvascular endothelial cells by meningitic Escherichia coli. Front Cell Infect Microbiol. 2018;8:448.

7. Dev A, lyer S, Razani B, Cheng G. NF-kappaB and innate immunity. Curr Top Microbiol Immunol. 2011;349:115-43.

8. Wang S, Peng L, Gai Z, Zhang L, Jong A, Cao H, et al. Pathogenic triad in bacterial meningitis: pathogen invasion, NF-kappaB activation, and leukocyte transmigration that occur at the blood-brain barrier. Front Microbiol. 2016;7:148.

9. Chi F, BO T, Wu CH, Jong A, Huang SH. Vimentin and PSF act in concert to regulate IbeA $+E$. coli $\mathrm{K} 1$ induced activation and nuclear translocation of NF-kappaB in human brain endothelial cells. PLoS One. 2012;7(4):e35862.

10. Koedel U, Bayerlein I, Paul R, Sporer B, Pfister HW. Pharmacologic interference with NF-kappaB activation attenuates central nervous system complications in experimental Pneumococcal meningitis. J Infect Dis. 2000;182(5):1437-45.

11. Ponting CP, Oliver PL, Reik W. Evolution and functions of long noncoding RNAs. Cell. 2009;136(4):629-41.

12. Fatica A, Bozzoni I. Long non-coding RNAs: new players in cell differentiation and development. Nat Rev Genet. 2014;15(1):7-21. 
13. Lee JT, Bartolomei MS. X-inactivation, imprinting, and long noncoding RNAs in health and disease. Cell. 2013;152(6):1308-23.

14. Ni W, Yao S, Zhou Y, Liu Y, Huang P, Zhou A, et al. Long noncoding RNA GAS5 inhibits progression of colorectal cancer by interacting with and triggering YAP phosphorylation and degradation and is negatively regulated by the m(6)A reader YTHDF3. Mol Cancer. 2019;18(1):143.

15. Zhang H, Li D, Zhang Y, Li J, Ma S, Zhang J, et al. Knockdown of IncRNA BDNF-AS suppresses neuronal cell apoptosis via downregulating miR-130b-5p target gene PRDM5 in acute spinal cord injury. RNA Biol. 2018;15(8):1071-80.

16. Du M, Yuan L, Tan X, Huang D, Wang X, Zheng Z, et al. The LPS-inducible IncRNA Mirt2 is a negative regulator of inflammation. Nat Commun. 2017:8(1):2049.

17. Zhou B, Qi F, Wu F, Nie H, Song Y, Shao L, et al. Endogenous retrovirusderived long noncoding RNA enhances innate immune responses via derepressing RELA expression. mBio. 2019. https://doi.org/10.1128/mBio. 00937-19

18. Xu B, Yang R, Fu J, Yang B, Chen J, Tan C, et al. LncRSPH9-4 facilitates meningitic Escherichia coli-caused blood-brain barrier disruption via miR17-5p/MMP3 axis. Int J Mol Sci. 2021;22(12):6343.

19. Sun Y, Zhong L, He X, Wang S, Lai Y, Wu W, et al. LncRNA H19 promotes vascular inflammation and abdominal aortic aneurysm formation by functioning as a competing endogenous RNA. J Mol Cell Cardiol. 2019;131:66-81.

20. Yang R, Huang F, Fu J, Dou B, Xu B, Miao L, et al. Differential transcription profiles of long non-coding RNAs in primary human brain microvascular endothelial cells in response to meningitic Escherichia coli. Sci Rep. 2016;6:38903

21. Broome HJ, Hebert MD. In vitro RNase and nucleic acid binding activities implicate coilin in U snRNA processing. PLoS One. 2012;7(4):e36300.

22. Enwerem II, Velma V, Broome HJ, Kuna M, Begum RA, Hebert MD. Coilin association with box C/D scaRNA suggests a direct role for the Cajal body marker protein in scaRNP biogenesis. Biol Open. 2014;3(4):240-9.

23. Janssens $S$, Beyaert R. Functional diversity and regulation of different interleukin-1 receptor-associated kinase (IRAK) family members. Mol Cell. 2003;11(2):293-302.

24. De Nardo D, Masendycz P, Ho S, Cross M, Fleetwood AJ, Reynolds EC, et al. A central role for the Hsp90.Cdc37 molecular chaperone module in interleukin-1 receptor-associated-kinase-dependent signaling by toll-like receptors. J Biol Chem. 2005;280(11):9813-22.

25. Wesche H, Gao X, Li X, Kirschning CJ, Stark GR, Cao Z. IRAK-M is a novel member of the Pelle/interleukin-1 receptor-associated kinase (IRAK) family. J Biol Chem. 1999;274(27):19403-10.

26. Carpenter S, Aiello D, Atianand MK, Ricci EP, Gandhi P, Hall LL, et al. A long noncoding RNA mediates both activation and repression of immune response genes. Science. 2013;341(6147):789-92.

27. Zhang P, Yu C, Yu J, Li Z, Lan HY, Zhou Q. Arid2-IR promotes NF-kappaBmediated renal inflammation by targeting NLRC5 transcription. Cell Mol Life Sci. 2021;78(5):2387-404.

28. Bao MH, Szeto V, Yang BB, Zhu SZ, Sun HS, Feng ZP. Long non-coding RNAs in ischemic stroke. Cell Death Dis. 2018;9(3):281

29. Johnson R. Long non-coding RNAs in Huntington's disease neurodegeneration. Neurobiol Dis. 2012;46(2):245-54.

30. Sun D, Yu Z, Fang X, Liu M, Pu Y, Shao Q, et al. LncRNA GAS5 inhibits microglial M2 polarization and exacerbates demyelination. EMBO Rep. 2017;18(10):1801-16.

31. Huarte M, Rinn JL. Large non-coding RNAs: missing links in cancer? Hum Mol Genet. 2010;19(R2):R152-61.

32. Wang $P, X u$ J, Wang $Y$, Cao X. An interferon-independent IncRNA promotes viral replication by modulating cellular metabolism. Science. 2017;358(6366):1051-5.

33. Dykes IM, Emanueli C. Transcriptional and post-transcriptional gene regulation by long non-coding RNA. Genomics Proteomics Bioinform. 2017;15(3):177-86.

34. Li L, Liu B, Wapinski OL, Tsai MC, Qu K, Zhang J, et al. Targeted disruption of Hotair leads to homeotic transformation and gene derepression. Cell Rep. 2013;5(1):3-12

35. Zhang X, Wang W, Zhu W, Dong J, Cheng Y, Yin Z, et al. Mechanisms and functions of long non-coding RNAs at multiple regulatory levels. Int J Mol Sci. 2019;20(22):5573.
36. Tay Y, Rinn J, Pandolfi PP. The multilayered complexity of ceRNA crosstalk and competition. Nature. 2014;505(7483):344-52.

37. Chen X, Zeng $K, X u M, H u X, L i u X, X u T$, et al. SP1-induced IncRNA-ZFAS1 contributes to colorectal cancer progression via the miR-150-5p/VEGFA axis. Cell Death Dis. 2018:9(10):982.

38. Enwerem II, Wu G, Yu YT, Hebert MD. Cajal body proteins differentially affect the processing of box C/D scaRNPs. PLoS One. 2015;10(4):e0122348.

39. Meier UT. RNA modification in Cajal bodies. RNA Biol. 2017;14(6):693-700

40. Cioce M, Lamond Al. Cajal bodies: a long history of discovery. Annu Rev Cell Dev Biol. 2005:21:105-31.

41. Platani M, Goldberg I, Swedlow JR, Lamond AI. In vivo analysis of Cajal body movement, separation, and joining in live human cells. J Cell Biol. 2000;151(7):1561-74

42. Koppe U, Suttorp N, Opitz B. Recognition of Streptococcus pneumoniae by the innate immune system. Cell Microbiol. 2012;14(4):460-6.

43. Lawrence T. The nuclear factor NF-kappaB pathway in inflammation. Cold Spring Harb Perspect Biol. 2009;1(6):a001651.

44. Rothschild DE, McDaniel DK, Ringel-Scaia VM, Allen IC. Modulating inflammation through the negative regulation of NF-kappaB signaling. J Leukoc Biol. 2018;103:1131.

45. Wang L, Qiao Q, Ferrao R, Shen C, Hatcher JM, Buhrlage SJ, et al. Crystal structure of human IRAK1. Proc Natl Acad Sci U S A 2017;114(51):13507-12.

46. Skaug B, Jiang X, Chen ZJ. The role of ubiquitin in NF-kappaB regulatory pathways. Annu Rev Biochem. 2009;78:769-96.

47. Lamothe B, Besse A, Campos AD, Webster WK, Wu H, Darnay BG. Sitespecific Lys-63-linked tumor necrosis factor receptor-associated factor 6 auto-ubiquitination is a critical determinant of I kappa B kinase activation. J Biol Chem. 2007;282(6):4102-12.

48. Chau A, Markley JC, Juang J, Tsen LC. Cytokines in the perinatal periodpart I. Int J Obstet Anesth. 2016;26:39-47.

49. Coureuil $M$, Lecuyer $H$, Bourdoulous S, Nassif X. A journey into the brain: insight into how bacterial pathogens cross blood-brain barriers. Nat Rev Microbiol. 2017;15(3):149-59.

50. Koelman DLH, Brouwer MC, van de Beek D. Targeting the complement system in bacterial meningitis. Brain. 2019;142(11):3325-37.

51. Liu $C$, Zheng $H$, Yang $M, X u Z$, Wang $X$, Wei $L$, et al. Genome analysis and in vivo virulence of porcine extraintestinal pathogenic Escherichia coli strain PCN033. BMC Genomics. 2015:16:717.

\section{Publisher's Note}

Springer Nature remains neutral with regard to jurisdictional claims in published maps and institutional affiliations.

Ready to submit your research? Choose BMC and benefit from

- fast, convenient online submission

- thorough peer review by experienced researchers in your field

- rapid publication on acceptance

- support for research data, including large and complex data types

- gold Open Access which fosters wider collaboration and increased citations

- maximum visibility for your research: over 100M website views per year

At BMC, research is always in progress.

Learn more biomedcentral.com/submissions 